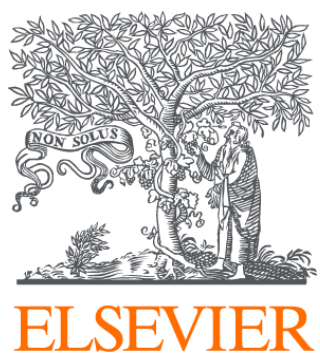

Since January 2020 Elsevier has created a COVID-19 resource centre with free information in English and Mandarin on the novel coronavirus COVID-

19. The COVID-19 resource centre is hosted on Elsevier Connect, the company's public news and information website.

Elsevier hereby grants permission to make all its COVID-19-related research that is available on the COVID-19 resource centre - including this research content - immediately available in PubMed Central and other publicly funded repositories, such as the WHO COVID database with rights for unrestricted research re-use and analyses in any form or by any means with acknowledgement of the original source. These permissions are granted for free by Elsevier for as long as the COVID-19 resource centre remains active. 


\title{
Severe Acute Respiratory Syndrome, Avian Influenza, the World Health Organization, and the Internet
}

\author{
D.O. Rodenstein
}

Service de Pneumologie, Cliniques Universitaires Saint-Luc, Université Catholique de Louvain, Brussels, Belgium.

During the epidemic of what came to be known as severe acute respiratory syndrome (SARS) and before the etiological agent had been identified, I was asked by a television journalist for an interview. It was 10 in the morning, and we agreed to meet at 2 that afternoon. The journalist arrived punctually with a film crew to record a short interview that was to be broadcast on the 7 o'clock news. Brimming with enthusiasm, he asked me for a photograph. Rather surprised, I enquired why he needed my picture. But no! It was not a photograph of me he wanted, but a picture of the Coronavirus! And so it was that I learned from a journalist that the virus responsible for SARS had been identified, a discovery I had been unaware of because the information had not been posted on the World Health Organization (WHO) website at 7 that morning, and I had been busy working during the rest of the morning.

SARS, a thoroughly modern plague, sowed panic all over the world. The progress of the disease became the hot topic of conversation in the workplace, at home, and among friends. The tally of new suspected or confirmed cases was reported on every television news bulletin with each new death sending a shiver through the whole population. During this first outbreak in humans, 8098 people developed SARS and 774 of them died as a result of the disease. ${ }^{1}$ When I inquired of the worried people around me whether they knew how many people were killed every year in Belgium by the common influenza virus and, in response to the general ignorance, told them the figure was $1500,{ }^{2}$ my assertion was met with general disbelief. The same conversation took place dozens of times. I had it with the journalist, but he failed even to mention this statistic during his broadcast.

After that, SARS became more aggressive than the common influenza virus, and the death rate rose sharply, I admit. I also accept that the precautions

\footnotetext{
Correspondence: Prof. D.O. Rodenstein.

Service de Pneumologie.

Cliniques Universitaires Saint-Luc. Université Catholique de Louvain.

Av. Hippocrate, 10. 1200 Bruxelles. Belgique.
}

E-mail: rodenstein@pneu.ucl.ac.be

Manuscript received December 26, 2005. Accepted for publication January 10, 2006. proposed by the WHO-with great fanfare-were probably justified. After all, health workers exposed on the front lines accounted for $21 \%$ of the cohort of people who contracted the disease. ${ }^{3}$ Nevertheless, in spite of all this, I cannot help feeling that the response to the situation was overblown. The existence of the Internet and the rapid appearance of a website that could provide minute-by-minute chapter and verse on every alarming report facilitated an intense media coverage that resembled a marvelous horror film script, particularly in light of the initial lack of information about the causative agent, the absence of any etiological treatment or preventative vaccine, and the climate of diffuse menace that affected the whole world in the wake of September 11, 2001. Moreover, it was a film in which everyone could feel like an actor from the comfort of their own sitting room sofa.

I cannot help making the point, however, that the WHO needed to recover its prestige after the criticisms that had been leveled at the organization 3 or 4 years ago, even in The Lancet. And no better scenario could have been imagined for this purpose than the SARS outbreak: worldwide anxiety, rapid response, effective guidelines, identification of the causative agent in under 3 months, and total containment of the epidemic within 6 months. The total number of lives lost was absurdly small for such an aggressive disease. ${ }^{1}$ Worldwide, the number of people who died as a result of SARS was only half the number who die every year of common influenza in a small country like Belgium.

I do not know if the epidemic would have been so easily contained without the WHO campaign. There is no way of knowing. However, several aspects of the process do draw my attention-the excessive level of anxiety generated, the importance of the media, and the absence of any rational perspective on the scale of the phenomenon relative to other epidemic infections and causes of death, such as the common influenza virus, tuberculosis, traffic accidents, and chronic obstructive pulmonary disease.

As I write these lines, the disease currently occupying center stage is avian influenza or fowl plague. Once again, the WHO did not hesitate to launch a massive campaign including daily updates, press 
releases, press conferences, and a website. And what are they telling us? A superficial analysis reveals a surprising degree of alarmism. The website moves quickly from information that could be of concern to people interested in the poultry industry (or bird rearing in general) in South-East Asia to the presentation of hypotheses with extremely serious implications for the health of the world population as a whole:

1. This virus would have great capacity for spontaneous mutation.

2. It would have great capacity to incorporate genetic material from other viruses and would, therefore, be able to cross the species barrier.

3. The appearance of an epidemic of common human influenza in the presence of the avian influenza virus could give rise to a highly contagious, super aggressive, super potent, super virus.

4. If this does not happen spontaneously, never fear! The passage through the pig, an animal that lives in close proximity to ducks and chickens, presents an ideal scenario for the much feared crossover between species.

5. Aha! Avian influenza virus has been found in a pig!

6. The passage through a pig is no longer necessary: cases of avian influenza contracted directly from hens (or ducks) have been found in both Vietnam and Thailand.

7. That pig was not infected-that piece of information was erroneous.

8. Even so, the much feared transmission from human to human is highly likely...

9. ....although that assertion has to be retracted shortly afterwards.

10. The world should prepare for a new and inevitable influenza pandemic that will leave the 50 million deaths of the Spanish flu epidemic (evoked with an agreeable frisson of horror) looking almost insignificant. (Although the WHO does not explain that current epidemiological models predict between 280000 and 650000 deaths for the next pandemic, a figure which, while in no way insignificant, is nonetheless a far cry from the 50 million deaths evoked.)

11. Indeed, it appears that 3 to 4 pandemics are required per century.

12. And it seems that we have been dodging the issue for a number of years so that the time is drawing near when we will have to face up to the big one.

13. Things could move even more quickly with the new virus (which is sequenced on a patient-by-patient basis to see whether it has mutated).

14. But to date no mutation has occurred.

15. The WHO insists that the situation is alarming, worrying, a cause for concern, and that the risk to human health is real and should not be underestimated...

16. ...only to declare some hours later that the situation is reassuring and that, above all, people should not panic.
17. It is, however, essential to prepare ourselves for the worst, to accumulate stocks of anti-influenza antiviral drugs, and to create special isolation units with sterile rooms and access corridors, negative pressure systems...

18. ... and to publish guidelines for the catastrophe...

19. ...which will in any case be useful since, if nothing happens this year, they may come in handy next year when the WHO launches its next campaign (just change the name of the suspicious virus and all the rest still applies).

20. And let us not forget that we have a new SARS campaign in reserve (during the 2003 outbreak there was already talk about the $\mathrm{H} 5 \mathrm{~N} 1$ being detected in 2 patients with suspected SARS, a father and son, on the February 19 and 20, 2003).

21. The total number of deaths caused by avian influenza on February 8, 2004 was 16 out of a total of 20 infected patients. ${ }^{4}$

I don't know whether when this article is published we will be plunged into the horror of a modern version of the plague of 1350, or whether avian influenza will no longer be a topic of conversation. But it all makes me wonder whether, as in the fairy tale, the emperor is wearing no clothes and nobody dares to say so.

The fateful effects of avian influenza have had considerable impact on the food industry in South-East Asia. And although every life is unique and irreplaceable, to date the harm to human health in terms of humanity as a whole has been very limited. The damaging effect of the WHO policy has, however, spread to the aviation industry, tourism, and, in general, everything related to the economic growth of SouthEast Asia. The events surrounding the SARS outbreak are a good example. ${ }^{5}$

The beneficial effects of the WHO policy seem to me to be difficult to establish. The generalized slaughter of fowl in South-East Asia was apparently inevitable and would have happened in any case. The ban on the import of poultry products from these countries would have been sufficient to trigger this, as we saw in Belgian during the dioxin crisis. The WHO campaign may not have been needed to achieve this objective. And I doubt that the WHO campaign has convinced the $\mathrm{H} 5 \mathrm{~N} 1$ virus that it had better not mutate. Nor do I believe that the pigs have been informed that the WHO is monitoring them closely. However, I do discern 2 or 3 direct beneficiaries of these campaigns: firstly—but for so little benefit-the pharmaceutical companies that manufacture the antiviral agents (far be it from me to point the finger); secondly, the poultry-producing countries that have taken the place on the world market of the South-East Asian producers who have been banned from participating in the world trade of these products; and lastly the WHO itself. It would be very interesting to study the evolution of the funds allocated to the WHO in the 5 years between 2003 and 2008 and to compare them with the subsidies received in the 5 years before 2003 . 
Let me add, lest I be accused of denying the utility of the WHO, that the effective action of this organization in matters of public health in developing countries is something that does not even need to be pointed out. What I am doing is simply wondering about the real justification for the campaigns in the mass media and on the Internet being undertaken by this venerable and prestigious institution over the last 2 years, and reflecting on the use it makes of the mass media. Can we reasonably say that there was a risk in the case of SARS? Can it be said that there is a high risk in the case of avian influenza? If the answer to these questions is yes, does the principle of caution not apply? Did the data available constitute sufficient justification for upsetting the lives of 300 or 400 million inhabitants of South-East Asia? Let us not forget that the economic consequences of the WHO campaign are facts not hypotheses, while the campaign is based on hypotheses rather than facts. In any case, to date the alarmist hypotheses have not been confirmed by events. What surprises me is the mix of alarmist and reassuring news in a single press report and the fact that possibilities, hypotheses, risks, and threats are mentioned that are subsequently not confirmed. ${ }^{6}$ Moreover, the use of language that would appear more appropriate for the headlines of a sensationalist tabloid by an organization like the WHO seems to me to be suspicious and worrying. ${ }^{3}$ Am I mistaken? I thought that it was at least necessary to make the point that the emperor may be wearing no clothes.

This article was drafted in December 2004. A year later the predictions made in a joking tone appear to have been confirmed. The pages of the WHO website directed at the general public $c^{7,8}$ are still filled with alarming and reassuring information, and it is still difficult to understand what is being said, to decide whether the best thing would be to flee on the first plane to Alaska or the Antarctic, or whether we can continue with our small and peaceful lives, taking care of our mother-in-law's health, worrying about the next football match between Real Madrid and Barcelona, or how to find a good Torta del Casar cheese to accompany the excellent ham received from a grateful patient as a Christmas present.

Meanwhile the Spanish influenza virus has been cloned and shows some characteristics ominously similar to H5N1 (which also means that it has many characteristics that are very different, but this is not mentioned!). Tons of antiviral agents have been bought that may turn out to be useless, and millions of pages of newspapers and magazines have been filled with articles written by journalists who are, in general, little prepared to interpret the information provided by ministries, scientific societies, international organizations, nongovernment organizations, medical experts, sociologists, and so on. The essential difference between the level of danger that would be present in the case of an epidemic (apparently high in the case of avian influenza) and the risk of an epidemic occurring (extremely low in the case of avian influenza) continues to escape most people, and this confusion contributes to a generalized feeling of anxiety and concern. In short, the situation has not changed much in a year.

And since it seems that the epidemic will not happen this season either, the banners, advertisements, pamphlets, posters, reports, and articles will have to be put away and held in readiness for next summer, when the journalists will have nothing more interesting to write about. It will, of course, be necessary to change the name and insert a photograph of the new bug!

If anyone is looking for a pastime other than solving sudokus, I recommend using Google to plot the curve representing the number of hits for avian influenza day by day. Simply enter the words "avian influenza" (inside quotes) together with the desired date using the following format: 25/12/2005. For example, on $07 / 10 / 2005$, the day after the publication of the genome of the Spanish influenza virus, there were over 3000 hits for "avian influenza," while the totals on preceding days were under 500. In passing, cast a glance at the commercial advertisements that appear on the right hand side of the screen. All of them deal with the subject of the famous "avian influenza." The reader will be met with one surprise after another-everything from traditional Chinese remedies and masks to antiviral agents and other interesting items.

\section{REFERENCES}

1. Available from: http://www.who.int/csr/sars/country/table2003_09_23/ en/print.html. Accessed January 11, 2004.

2. Available from: http://www.iph.fgov.be/flu/fr/11FR.htm. Accessed January 11, 2004.

3. Available from: http://www.who.int/csr/don/2003_07_04/en/ Accessed January 11, 2004.

4. Available from: http://www.who.int/csr/disease/avian_inflenza/ country/cases_table_2004_02_06/en/print.html Accessed February 7, 2004.

5. Available from: http://www.commerce-exterieur.gouv.fr/minsier presse/dos_presse_030605/fiche_2.htm Accessed January 11, 2004.

6. Available from: http://www.who.int/mediacentre/releases/2004/ pr7/en/ Accessed February 2, 2004.

7. Available from: http://www.who.int/csr/disease/avian_influenza/ Timeline_28_10a.pdf Accessed December 25, 2005.

8. Available from: http://www.who.int/csr/disease/avian_influenza/ avian_faqs/en/index.html\#present Accessed December 25, 2005. 